\title{
Roles of Nickel Layer Deposition on Surface and Electric Properties of Carbon Fibers
}

\author{
Byung-Joo Kim, Woong-Ki Choi, Kyong-Min Bae, ${ }^{\dagger}$ Cheol-Whan Moon, ${ }^{\ddagger}$ Heung Sub Song, ${ }^{\S}$ \\ Jong Kyoo Park, ${ }^{\S}$ Jae Yeol Lee, ${ }^{\S}$ Seung-Soon Im,,$*$ and Soo-Jin Park ${ }^{\dagger, *}$ \\ Carbon Valley R\&D Division, Jeonju Institute of Machinery and Carbon Composites, Jeonju, Jeollabuk-do 561-844, Korea \\ ${ }^{\dagger}$ Department of Chemistry, Inha University, Incheon 402-751, Korea. E-mail: sjpark@inha.ac.kr \\ ‡ivision of Chemical Engineering, Hanyang University, Seoul 133-791, Korea.*E-mail: imss007@hanyang.ac.kr \\ ${ }^{\S}$ Agency for Defense Development, Daejeon 305-600, Korea \\ Received October 1, 2011, Accepted March 28, 2011
}

\begin{abstract}
Electroless plating of metallic nickel on carbon fiber surfaces was carried out to control specific electric resistivity of the fibers, and the effects of the nickel content and coating thickness on the electric properties were studied. The structural and surface properties of the carbon fibers were characterized using X-ray diffraction (XRD), scanning electron microscopy (SEM), and X-ray photoelectron spectroscopy (XPS). The specific resistivity of the fibers was measured using a four-point probe testing method. From the XPS results, the oxygen and $\mathrm{Ni}$ atomic ratio of the fibers was greatly enhanced as the plating time increased. Additionally, it was observed that the specific electric resistivity decreased considerably in the presence of metallic nickel particles and with the formation of nickel layers on carbon fibers.
\end{abstract}

Key Words : Metal plating, Specific resistivity, Carbon fibers

\section{Introduction}

With the rapid development of the electronics industry, especially as it pertains to personal computers and mobiles phones, the problem of electromagnetic interference (EMI) is increasing. One effective technique to solve the EMI problem is to increase the electrical conductivity (or decrease specific electric resistivity) of the plastic cages of electric devices. ${ }^{1-3}$

Carbon fibers are one of the most important and advanced reinforcements. They have a low coefficient of thermal expansion and are characterized by their low density and high modulus. Additionally, these fibers are strong. These properties make carbon fibers an ideal material for use in heavy-duty aircraft, automotive parts, and electrical instruments and in the chemical industry. However, as the specific electric resistivity of carbon fibers is much higher than that of metals, the formulation of low-resistivity carbon fibers is necessary to achieve feasible shielding. ${ }^{4-11}$

To decrease the specific electric resistivity of carbon fibers, various metal plating techniques have been applied using $\mathrm{Ni},{ }^{12} \mathrm{Cu},{ }^{13} \mathrm{Zn},{ }^{14} \mathrm{Pt},{ }^{15}$ and Ag. ${ }^{16}$ Among these techniques, electroless Ni-plating is viable as a low-resistive type of filler for EMI shielding. Electroless Ni-plating has the advantages of good metal deposition, very low electric resistivity and shielding effectiveness, and applicability to non-conducting materials with complicated shapes. ${ }^{6}$

The nickel plating process is based on a redox reaction in which the reducing agent is oxidized and $\mathrm{Ni}^{2+}$ ions are reduced on the substrate surface. When the first layer of nickel is deposited, it serves as a catalyst for the process. As a result, a linear relationship between the coating thickness and time normally occurs. During electroless plating, carbon fiber surfaces are metalized when exposed to plating solutions, coating molten salt in the presence of a reductant.

Therefore, in this work, electroless Ni-plating was conducted on carbon fibers to control the specific electric resistivity of the fibers for use as low-resistive (or high conductive) fillers in a composite system, and its effect on the structural and surface properties of the fibers was also investigated.

\section{Experimental Section}

Sample Preparation. The carbon fibers used in this work were unsized and untreated polyacylonitrile (PAN)-based carbon fibers manufactured by Taekwang Ind. of Korea (TZ$307,12 \mathrm{~K}$ ). The average diameter of these carbon fibers was approximately $7 \mu \mathrm{m}$, and typical tensile modulus and strength were about 245 and $3.5 \mathrm{GPa}$, respectively. ${ }^{17}$

Electroless Ni plating was performed on a $10 \mathrm{~cm}$ carbon fiber using nickel chloride as the source of nickel and sodium hypophosphite as the reducing agent. Table 1 shows the bath

Table 1. Plating Bath Composition and Conditions for Electroless Ni Plating

\begin{tabular}{ccc}
\hline & $\mathrm{NaPH}_{2} \mathrm{O}_{2} \cdot \mathrm{H}_{2} \mathrm{O}$ & $15.5 \mathrm{~g} / \mathrm{L}$ \\
& $\mathrm{NiCl}_{2} \cdot 6 \mathrm{H}_{2} \mathrm{O}$ & $28.5 \mathrm{~g} / \mathrm{L}$ \\
Composition & $\mathrm{NaC}_{6} \mathrm{H}_{5} \mathrm{O}_{7} \cdot 6 \mathrm{H}_{2} \mathrm{O}$ & $43.5 \mathrm{~g} / \mathrm{L}$ \\
& $\mathrm{NH}_{4} \mathrm{Cl}$ & $28 \mathrm{~g} / \mathrm{L}$ \\
& $\mathrm{NaOH}$ & $\mathrm{pH}$ adjustment \\
\hline \multirow{3}{*}{ Condition } & $\mathrm{pH}$ & $5-6.2$ \\
& Temperature & $50-60^{\circ} \mathrm{C}$ \\
& Plating time & $0-30 \mathrm{~min}$ \\
\hline
\end{tabular}


composition. Before the plating, the impurities of the carbon fibers were removed by immersing them in nitric acid (3 mol) for $30 \mathrm{~h}$.

A two-step pretreatment consisting of sensitization and activation was used to catalyze the carbon fibers. The sensitizer and activator were stannous chloride/hydrochloric acid and palladium chloride/hydrochloric acid, respectively, which assisted with the formation of a nucleus to plate the metal onto the surface of the carbon fibers. The sensitized carbon fibers were added to the solution of the reducing agent. Nickel chloride was used as the source of metal ions, sodium hypophosphite was the reducing agent, and sodium citrate was used as a complexing agent to control the $\mathrm{pH}$ of the bath during the plating process. The electroless plating was performed on a hot plate with a magnetic stirrer while maintaining the temperature of the bath at $60 \pm 2{ }^{\circ} \mathrm{C}$. Samples were prepared at different plating times: Ni-1, 1 min; Ni-5, 5 min; Ni-10, $10 \mathrm{~min}$; Ni-30, 30 min. $^{8}$

Characterization. The changes in the structural properties of the carbon fibers before and after the Ni electroless plating processes were characterized by Wide-angle X-ray diffraction (XRD). The XRD patterns of Ni-plated carbon fibers were obtained with a Rigaku Model D/MAX-III B diffractometer equipped with a rotation anode and $\mathrm{CuK} \alpha$ radiation $(\lambda=0.15418 \mathrm{~nm})$ as the source to measure the interlayer spacing $\left(d_{002}\right)$.

The surface properties including surface functional groups and morphologies were studied by X-ray photoelectron spectroscopy (XPS) and scanning electron micrographs (SEM). An XPS experiment was performed using a VG Scientific ESCA LAB MK-II spectrometer equipped with an $\mathrm{Mg}-\mathrm{K} \alpha \mathrm{X}$-ray source $(1253.6 \mathrm{eV})$. The pressure inside the chamber was held below $5 \times 10^{-8}$ Torr during analysis. The survey XPS spectra were recorded at a $40^{\circ}$ take-off angle. The $\mathrm{C}_{1 \mathrm{~S}}$ electron binding energy was referenced at 284.6 $\mathrm{eV} .{ }^{18}$ Changes in the surface morphology of Ni-plated carbon fibers were examined using SEM (JEOL JSM-840A).

The four-point probe method was used in the measurement of the specific resistivity of a single fiber. A single fiber was cemented with silver paint to Pt leads that were printed onto an alumina plate. Silver paint was used in an effort to minimize measurement error. The electric resistivity of the carbon fibers before and after Ni plating was determined by measuring the specific resistivity (or volume resistivity) using a digital multi-meter (MCP-T610, Mitsubishi Chemical Corporation of Japan). The measuring room was maintained at a temperature of $25\left( \pm 2{ }^{\circ} \mathrm{C}\right)$ and a relative humidity of $55( \pm 2 \%)$. The specific resistance was calculated taking into account the diameter and length of each fiber.

Specific electrical resistivity (SER, or volume resistivity) was calculated using the following equation:

$$
\operatorname{SER}(\Omega \cdot \mathrm{cm})=(\mathrm{WT} / \mathrm{L}) \times(\mathrm{R})
$$

Here, $\mathrm{L}$ is the length between terminals, $\mathrm{T}$ and $\mathrm{W}$ are the width and thickness of the sample, respectively, and $\mathrm{R}$ is the electric resistivity. The thickness of the sample was measured with a micrometer (model 2046F, Mitutoyo Co., Japan).

\section{Results and Discussion}

Electroless Ni Plating. Electroless Ni-plating, in contrast to nickel electroplating, does not require an external electric current to produce a deposit. Deposition occurs in an aqueous solution containing metal ions, a reducing agent, and catalysts. Chemical reactions on the surface of the catalytic part being plated lead to deposition of the metal or alloy. The most common reducing agent used (also used here) is sodium hypophosphite, whose chemical reaction consists of two types simultaneous reactions:

The first reaction involves the cathodic reaction of $\mathrm{Ni}^{2+}$, $\mathrm{H}^{+}$, and $\mathrm{H}_{2} \mathrm{PO}_{2}^{-}$or the deposition of Ni-P alloy and the production of hydrogen:

$$
\begin{gathered}
\mathrm{Ni}^{2+}+2 \mathrm{e}^{-} \rightarrow \mathrm{Ni} \\
2 \mathrm{H}^{+}+2 \mathrm{e}^{-} \rightarrow \mathrm{H}_{2} \\
\mathrm{H}_{2} \mathrm{PO}_{2}^{-}+2 \mathrm{H}^{+}+\mathrm{e}^{-} \rightarrow \mathrm{P}+2 \mathrm{H}_{2} \mathrm{O}
\end{gathered}
$$

The second reaction is the anodic oxidation of $\mathrm{H}_{2} \mathrm{PO}_{2}^{-}$, that is,

$$
\mathrm{H}_{2} \mathrm{PO}_{2}^{-}+\mathrm{H}_{2} \mathrm{O} \rightarrow \mathrm{H}_{2} \mathrm{PO}_{3}^{-}+\mathrm{H}+\mathrm{H}^{+}+\mathrm{e}^{-}
$$

The $\mathrm{Ni}^{2+}$ ions adsorbed in the presence of the activated fiber surfaces were reduced by the adsorbed $\mathrm{H}^{+}$ions and the plating proceeds, so long as there is sufficient availability of metal ions and reducing agent. The reduction of nickel is confirmed by the formation of hydrogen from the fiber surfaces. In this case, an initially very vigorous reaction was observed during the plating reaction. ${ }^{19-22}$

Figure 1 shows the content of nickel on the carbon fibers as a function of the electroless plating time. It shows that the content of nickel increases with an increase in the plating time. It is interesting that $\mathrm{Ni}$ deposition occurred rapidly up to $1 \mathrm{~min}$ of plating time. In the initial state of Ni plating (or deposition), the reaction normally occurs very severely due to the $\mathrm{Pd} / \mathrm{Sn}$ catalysts introduced on carbon fiber surfaces, resulting in the formation of island-like Ni clusters. Then, Ni content increases steadily to $10 \mathrm{~min}$ of plating time until the formation of perfect $\mathrm{Ni}$ layers on the fibers. After layer formation, Ni content increases slowly. ${ }^{23}$

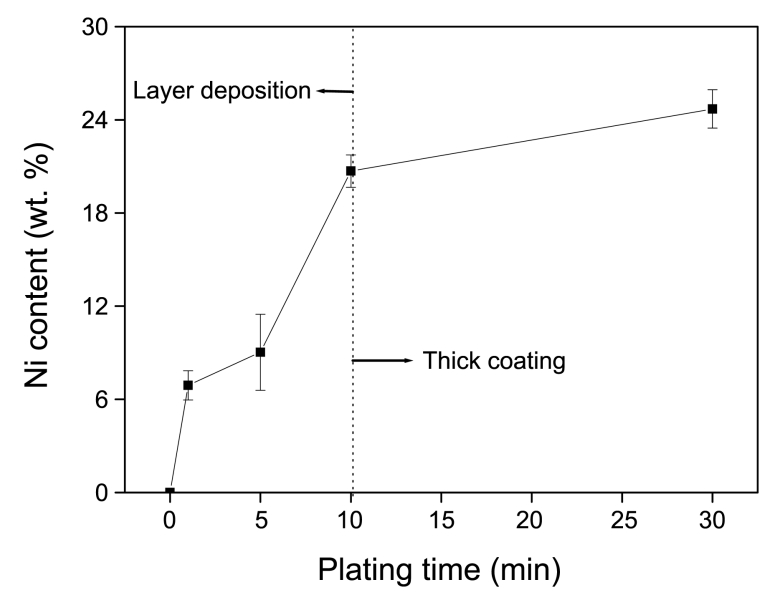

Figure 1. Ni content on carbon fibers as a function of plating time. 


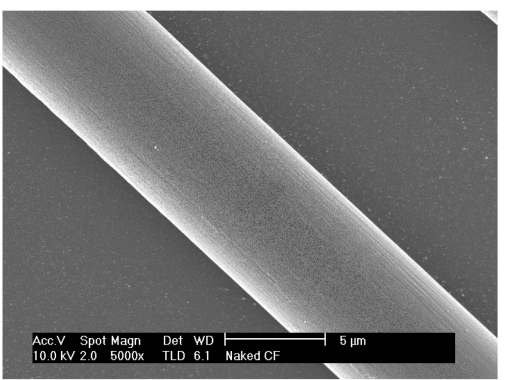

(a)

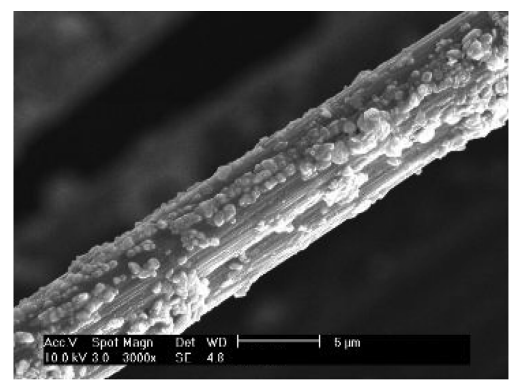

(b)

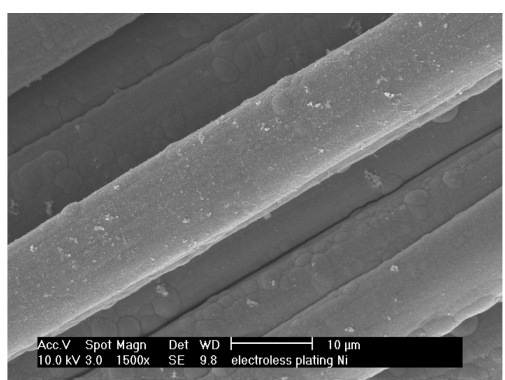

(c)

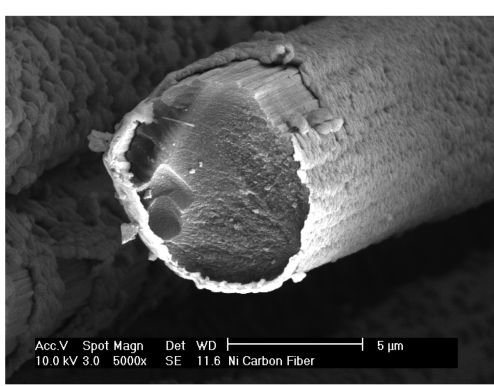

(d)

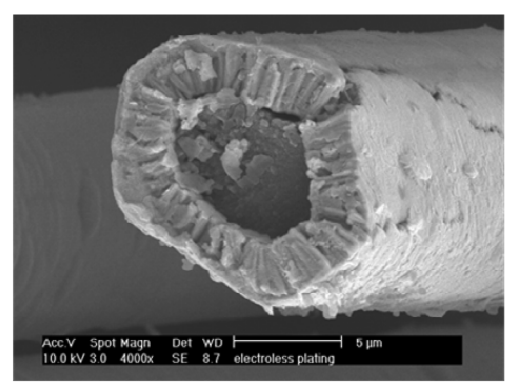

(e)

Figure 2. SEM micrographs of carbon fibers: (a) as-received of side view, (b) 5 min of side view, (c) 10 min of side view, (d) 10 min of cross-section, (e) 30 min of cross-section.

Surface Morphologies. Figure 2 shows SEM micrographs of the $\mathrm{Ni} /$ carbon fibers as a function of plating time for observation of the surface morphologies. Figures 2(a), (b), (c) show the side view of as-received, $5 \mathrm{~min}$ and $10 \mathrm{~min} \mathrm{Ni-}$ plated carbon fibers, respectively, and Figures 2(d) and (e) are the cross-section images of fibers plated for $10 \mathrm{~min}$ and $30 \mathrm{~min}$. The as-received carbon fibers (a) had a smooth surface and uniform diameters. In case of the 5 min sample (b), Ni particles were deposited irregularly. It was found that perfect Ni layers were coated on carbon fibers in the sample shown in Figure 2(c), and the thickness of the Ni layer was enhanced in the sample shown in (e) compared with the sample shown in (d). These results show good agreement with the data of Figure 1. In Figure 1, Ni content speedily increased up to $10 \mathrm{~min}$ and then gently increased to $30 \mathrm{~min}$. Abraham et al. ${ }^{24}$ reported that metal plating on carbon fibers began at scratches and fine cracks that existed on the surface of carbon fibers and were connected to each other. Ni plating in this system is understandable through a similar mechanism of Ni loading that can be applied on the carbon fibers. In the Ni-5 sample, an island-like Ni layer was observed, as shown Figure 2(b). On the other hand, in the Ni-10 (c), a very smooth surface like that of the as-received samples was observed. This result indicates that island-like Ni clusters got together and formed a layer. In the Ni-30 sample (e), the diameter of the fibers is around 6-7 $\mu \mathrm{m}$ and the thickness of the nickel layer is $2-3 \mu \mathrm{m}$. As a result, perfect Ni-layers formed and fully covered the carbon fiber surfaces.

Structural Properties. In order to observe the microstructural properties of the carbon fibers after electroless $\mathrm{Ni}$ plating at different times, XRD patterns were used and are shown in Figure 3. The presence of $\mathrm{Ni}(111)$ (peak at $45(2 \theta)$ )

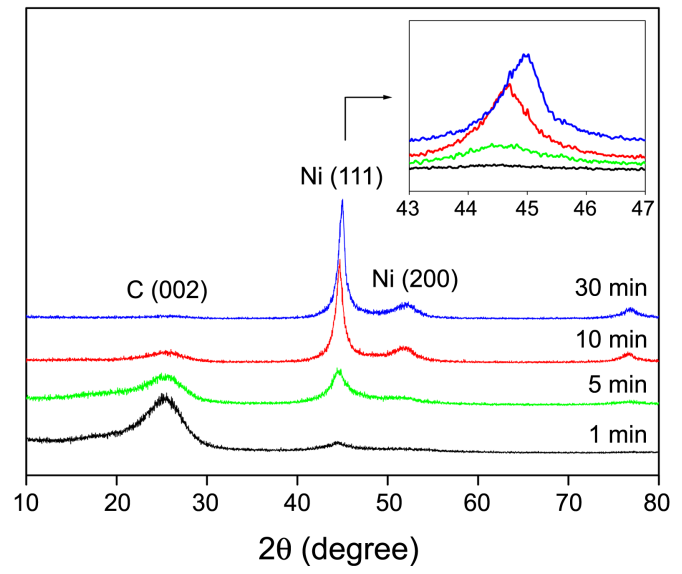

Figure 3. X-ray diffraction patterns of the Ni-plated carbon fibers as a function of plating time (The magnification of the pattern from 2 theta $=43$ to 47 degree is located in right-up side of the figure).

and $\mathrm{Ni}(200)$ (peak at $52(2 \theta)$ ) was observed, and it was found that $\mathrm{Ni}(111)$ and $\mathrm{Ni}(200)$ peaks increased with increasing plating time. Otherwise, the $\mathrm{C}(002)$ peak decreased after $\mathrm{Ni}$ plating because Ni layers were covered with carbon fiber surfaces.

It is interesting to note that the $\mathrm{Ni}(111)$ peaks were shifted to the right side, indicating that the distance between the layers had become close. This result indicates that the microstructure of the Ni layers plated for $30 \mathrm{~min}$ is denser than that of the layers in the 10 min sample. As can be seen in Figures 1 and 2, we proposed that Ni plating occurred in island-like structures initially and propagated to layer shapes followed by thick coating. During these reactions, the structure of the Ni layer on carbon fibers becomes thicker 
Table 2. XRD Results and Nickel Crystal Size $\left(\mathrm{L}_{\mathrm{c}}\right)$ of Electroless Ni-plated Carbon Fibers with Plating Time

\begin{tabular}{ccccr}
\hline & Brag angle $(\theta)$ & $d_{(111)}(\AA)$ & FWHM & \multicolumn{1}{c}{$\mathrm{L}_{\mathrm{c}}(\mathrm{nm})$} \\
\hline $\mathrm{Ni}-1$ & 22.20 & 2.043 & 0.86 & $9.9( \pm 0.19)$ \\
$\mathrm{Ni}-5$ & 22.30 & 2.038 & 0.74 & $11.4( \pm 0.26)$ \\
$\mathrm{Ni}-10$ & 22.35 & 2.025 & 0.59 & $14.2( \pm 0.29)$ \\
$\mathrm{Ni}-30$ & 22.47 & 2.015 & 0.61 & $14.0( \pm 0.34)$ \\
\hline
\end{tabular}

and denser. To identify the micro-structure of the Ni layers on the carbon fibers in detail, the $d_{(111)}$ space and crystal size $\left(\mathrm{L}_{\mathrm{c}}\right)$ were studied and are listed in Table 2. It was observed that when the Ni-plating time increased at $30 \mathrm{~min}$, a decrease of $d$-spacing from $2.043 \AA$ to $2.015 \AA$ was obtained. The crystal size $\left(L_{c}\right)$ of the Ni-plated carbon fibers increased dramatically as the plating time increased up to $10 \mathrm{~min}$. After 10 min of plating time, the crystal size $\left(\mathrm{L}_{\mathrm{c}}\right)$ was not further increased.

Surface Properties. Wide-scan spectra in the binding energy range of $0-1200 \mathrm{eV}$ were obtained to identify the surface elements present and to conduct a quantitative analysis. The XPS wide-scan spectra of the two carbon fiber samples (as-received and Ni-30 samples) are shown in Figure 4 . The spectra distinctly show the carbon, oxygen, and nickel peaks of the samples. It was found that the peak intensity of the $\mathrm{O}_{1 \mathrm{~s}}(\mathrm{BE}=532.8 \mathrm{eV})$ and the $\mathrm{Ni}_{2 \mathrm{p}}(\mathrm{BE}=857.6$ $\mathrm{eV})$ peaks of the Ni-plated carbon fibers were higher than those of the as-received carbon fibers. The enhancement of the $\mathrm{O}_{1 \mathrm{~s}}$ peaks on the carbon fiber surface can be explained in that the severe plating conditions, such as high $\mathrm{pH}$ and temperature, may affect the surface structures and chemical compositions, resulting in an introduction of oxygen-containing groups on the carbon surfaces. Figure 5 shows the expanded scale of the $\mathrm{O}_{1 \mathrm{~s}}$ XPS spectra of the (a) as-received and (b) electroless Ni-plated carbon fibers after $30 \mathrm{~min}$ of plating. The $\mathrm{O}_{1 \mathrm{~s}}$ spectra of the as-received sample reveal the presence of two peaks. Peak 1 (B.E. $530.6 \mathrm{eV}$ ) corresponds to the $\mathrm{C}=\mathrm{O}$ group (ketone, lactone, and carbonyl) or the $-\mathrm{OH}$ group, and peak 2 (B.E. $532.6 \mathrm{eV}$ ) corresponds to the O-C-O group. The spectra of the Ni-plated carbon fibers reveal the

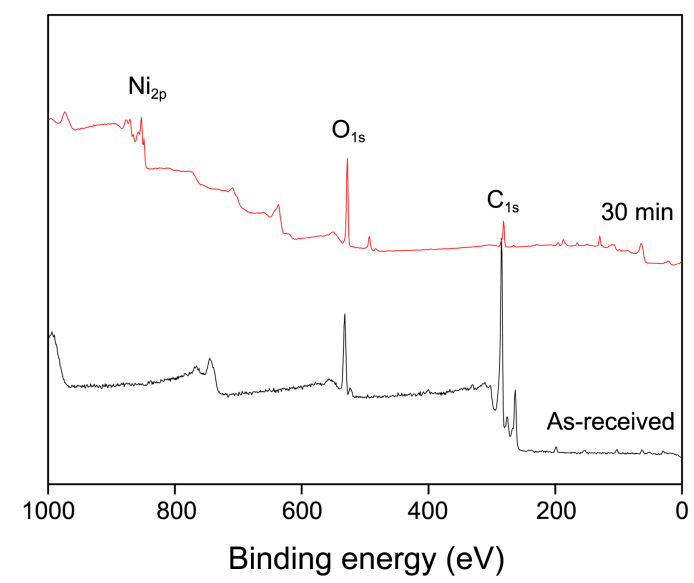

Figure 4. XPS spectra of electroless Ni-plated carbon fibers with plating time: (a) as-received, (b) $30 \mathrm{~min}$
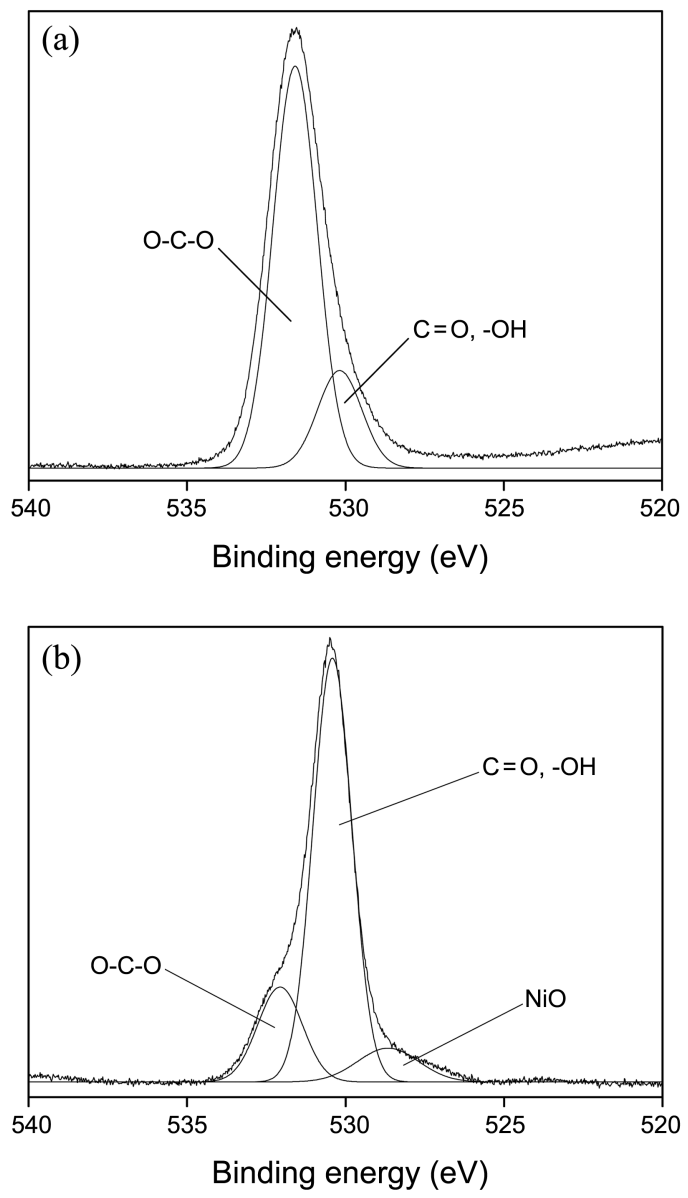

Figure 5. High resolution $\mathrm{O}_{1 \mathrm{~s}}$ spectra of the as-received and electroless Ni-plated carbon fibers surfaces: (a) as-received, (b) 30 $\min$.

presence of three peaks corresponding to the $\mathrm{NiO}$ group (B.E. $527.8 \mathrm{eV}$ ), $\mathrm{C}=\mathrm{O}$ or $-\mathrm{OH}$ groups (B.E.531.6 eV), O-C$\mathrm{O}$ groups (B.E. $532.6 \mathrm{eV}$ ). It was found that the center of the $\mathrm{C}=\mathrm{O}$ or $-\mathrm{OH}$ peak was shifted to the high binding energy region after Ni-plating. This result indicates that the binding energy between elements ' $\mathrm{O}$ ' and ' $\mathrm{C}$ ' is enhanced due to the introduction of Ni-particles on the carbon surfaces. As can be seen in Figure 5(b) $\mathrm{NiO}$ peak was newly formed and it can be understood that the source of elemental oxygen is the $\mathrm{O}-\mathrm{C}-\mathrm{O}, \mathrm{C}=\mathrm{O}$ or $-\mathrm{OH}$ of the as-received carbon fibers. From Figure 5, the peak of O-C-O was decreased and the peak of $\mathrm{C}=\mathrm{O}$ or $-\mathrm{OH}$ was enhanced after the Ni plating. So, it can be concluded that the introduction of $\mathrm{Ni}$ particles helps the formation of $\mathrm{C}=\mathrm{O}$ or $\mathrm{NiO}$ by reducing O-C-O. And, some of the $\mathrm{C}=\mathrm{O}$ also contributes to the formation of $\mathrm{NiO}$, resulting in an increase of the binding energy of the $\mathrm{C}=\mathrm{O}$ peaks.

The experimental XPS results show that the carbon content of the Ni-plated fibers decreased when they were plated with nickel, whereas the oxygen and nickel contents of the plated fibers were higher compared with those of the asreceived fibers. These active groups on the carbon fiber surfaces produced through nickel plating may help to change the polarity and the functionality of the fiber surfaces.

Electrical Properties. Figure 6 shows the specific electric 


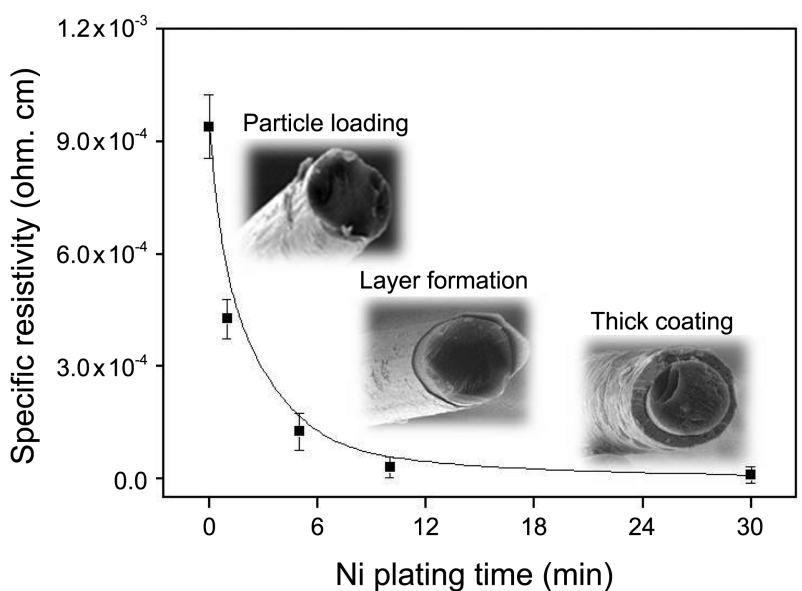

Figure 6. Specific resistivity of Ni-plated carbon fibers as a function of Ni plating time.

resistivity of the electroless Ni-plated carbon fibers with respect to the plating time. It was observed that the electrical conductivity increased in proportion to the Ni-electroplating time. It was also found that the specific electric resistivity was significantly reduced up to $10 \mathrm{~min}$, past which time no additional decrease occurred up to $30 \mathrm{~min}$. This was most likely due to the formation of perfect Ni-layers on the carbon fibers after a specific point of the process.

Normally, electroless plating is achieved through three steps: (1) the introduction of nuclei, (2) the formation of metallic islands (or particles), and (3) the formation of perfect layers. In Figure 6, the specific resistance of the Ni-1 sample was decreased compared with that of as-received sample, indicating that the electric network on the fiber surfaces was highly enhanced in the Ni-1 sample even though the Ni peaks from the XRD results were not strong. ${ }^{12}$ It can be understood that the island-like Ni loading in Ni-1 sample strongly leads to a reduction of the electric resistivity of the carbon fibers, though the metallic layer on the fiber surfaces does not form yet, as confirmed by the data in Figures 1 and 2 .

These phenomena have been observed and it is concluded that electric resistivity can be controlled by electroless $\mathrm{Ni}$ plating when there forms a perfect layer, as in electric networks. Excessive plating conditions make the microstructure of the Ni-layers and the crystal sizes of the nickel particles dense and small, resulting in super-low specific electric resistivity and even saturation state.

\section{Conclusions}

In this work, electroless Ni-plating on PAN-based carbon fiber surfaces was carried out to control the specific electric conductivity of carbon fibers; the effects of the nickel content and the surface properties on the electric resistivity were studied. The results show that the specific resistivity of the Ni-plated carbon fibers decreased as the plating time and thickness of the Ni layers increased. It was also found that perfect Ni layers on carbon fibers can be formed at a plating time of $10 \mathrm{~min}$ in this system.

Acknowledgments. This research was supported by a grant from the Fundamental R\&D Program for Technology of World Premier Materials funded by the Ministry of Knowledge Economy, Republic of Korea. This subject is supported by Korea Ministry of Environment as "The Ecotechnopia 21 Project”.

\section{References}

1. Dhawan, S. K.; Singh, N. Venkatachalam, S. Synth. Met. 2001, $125,389$.

2. Gu Z.; Li, C.; Wang, G.; Zhang, L.; Cheng, Q.; Li, X.; Wang, W.; Jin, S. J. Ind. Eng. Chem. 2010, 16, 10.

3. Li, L. C.; Liu, H.; Wang,Y.; Jiang, J.; Xu, F. J. Colloid Interface Sci. 2008, 322, 265.

4. Seo, M. K.; Park, S. J. J. Colloid Interface Sci. 2009, 330, 237.

5. Donnet, J. B.; Bansal, R. C. Carbon Fibers, 2th ed.; Marcel Dekker: New York, 1990.

6. Lee, S.; Kim, J.; Ku, B. C.; Kim, J.; Chung, Y. Carbon Lett. 2011, $12,26$.

7. Ray, B. C. J. Colloid Interface Sci. 2006, 298, 111.

8. Hoa, K. K. C.; Lamorinierea, S.; Kalinkab, G.; Schulzb, E.; Bismarcka, A. J. Colloid Interface Sci. 2007, 313, 476.

9. Ling, Q.; Sun, J.; Zhao, Q.; Zhou, Q. Mat. Sci. Eng: B 2009, 162, 162.

10. Park, S. J.; Chang, Y. H.; Moon, C. W.; Suh, D. H.; Im, S. S.; Kim, Y. C. Bull. Korean Chem. Soc. 2010, 31, 335.

11. Yun, J. H.; Kim, B. H.; Yang, K. S.; Bang, Y. H.; Kim, S. R.; Woo H. G. Bull. Korean Chem. Soc. 2009, 30, 2253.

12. Kim, S.; Park, S. J. Electrochim. Acta 2008, 53, 4082.

13. Kim, B. J.; Choi, W. K.; Song, H. S.; Park, J. K.; Lee, J. Y.; Park, S. J. Carbon Lett. 2008, 9, 105.

14. Park, S. J.; Kim, B. J.; Lee, Y. S.; Cho, M. J. Int. J. Hydrogen Energy 2008, 33, 1706.

15. El hajjami, A.; Gigandet, M. P.; De Petris-Wery, M.; Catonne, J. C.; Duprat, J. J.; Thiery, L.; Raulin, F.; Starck, B.; Remy, P. Appl. Surf. Sci. 2008, 255, 1654.

16. Papadimitriou, S.; Tegou, A.; Pavlidou, E.; Armyanov, S.; Valova, E.; Kokkinidis, G.; Sotiropoulos, S. Electrochim. Acta 2008, 53, 6559.

17. Park, S. J.; Seo, M. K.; Rhee, K. Y. Mat. Sci. Eng: A 2003, 356, 219.

18. Park, S. J.; Jang, Y. S. J. Colloid Interface Sci. 2003, 263, 170.

19. Smith, F. Metal Finishing 1979, 60.

20. Kim, K. S.; Shim, Y. S.; Kim, B. J.; Meng, L. Y.; Lee, S. Y.; Park, S. J. Carbon Lett. 2010, 11, 235.

21. Han, K. P.; Fang, J. L. J. Appl. Electrochem. 1996, 26, 1273.

22. Yu, X.; Wang, H.; Yang, Z.; Yin, P.; Xin, X. Appl. Surf. Sci. 2000, $158,335$.

23. Kim, B. J.; Lee, Y. S.; Park, S. J. Int. J. Hydrogen Energy 2008, $33,4112$.

24. Abraham, S.; Pai, B. C.; Satyanarayana, K. G.; Vaidyan, V. K. J. Mater. Sci. 1990, 25, 2839. 